\title{
Control of glycemia and blood pressure in British adults with diabetes mellitus and subsequent therapy choices: a comparison across health states
}

Finlay A. McAlister ${ }^{1,2^{*}}$ (D, Brendan Cord Lethebe ${ }^{3}$, Caitlin Lambe ${ }^{3}$, Tyler Williamson ${ }^{3}$ and Mark Lowerison ${ }^{3}$

\begin{abstract}
Background: To examine the intensity of glycemic and blood pressure control in British adults with diabetes mellitus and whether control levels or treatment deintensification rates differ across health states.

Methods: Retrospective cohort study using primary care electronic medical records (the United Kingdom Health Improvement Network Database) for adults with diabetes diagnosed at least 6 months before the index HbA1C and systolic blood pressure (SBP) measurements (to give their primary care physicians time to achieve treatment goals). We used prescribing records for 6 months pre/post the index measurements to determine who had therapy subsequently deintensified (based on "glycemic therapy score" and "antihypertensive therapy score" derived from number and dosage of medications).

Results: Of 292,170 individuals with diabetes, $\mathrm{HbA1C}<6 \%$ or SBP $<120 \mathrm{mmHg}$ after at least 6 months of management was less common in otherwise fit patients (15.0 and 12.7\%) than in those who were mildly frail (16.6 and $13.2 \%$ ) or moderately-severely frail $(20.2$ and $17.0 \%$, both $p<0.0001)$. In the next 6 months, only $44.7 \%$ of those with $\mathrm{HbA} 1 \mathrm{C}<6 \%$ had glycemic therapy reduced (44.4\% of fit, $47.1 \%$ of mildly frail, and $41.5 \%$ of moderate-severely frail patients) and $39.8 \%$ of those with SBP $<120$ had their antihypertensives decreased (39.3\% of fit, $43.0 \%$ of mildly frail, and $46.7 \%$ of moderate-severely frail patients). On the other hand, more individuals exhibited higher than recommended levels for $\mathrm{HbA1C}$ or SBP after the first 6 months of therapy $(37.3,33.4$, and 31.3\% of fit, mildly frail, and moderately-severely frail patients had $\mathrm{HbA} 1 \mathrm{C}>7.5 \%$ and $46.6,51.4$, and $48.5 \%$ had SBP $>140 \mathrm{mmHg}$ ). The proportions of patients with $\mathrm{HbA} 1 \mathrm{C}$ or SBP out of recommended treatment ranges changed little 6 months later despite frequent (median 14 per year) primary care visits.
\end{abstract}

Conclusions: Glycemic and hypertensive control exhibited statistically significant but small magnitude differences across frailty states. Medication deintensification was uncommon, even in frail patients below SBP and HbA1C targets. SBP levels were more likely to be outside recommended treatment ranges than glycemic levels.

Trial registration As this study is a retrospective secondary analysis of electronic medical record data and not a health care intervention trial it was not registered

Keywords: Glycemic control, Hypertension, Database research, Pharmaco-epidemiology, Diabetes mellitus, Treatment, Targets, Deintensification

\footnotetext{
*Correspondence: Finlay.McAlister@ualberta.ca

${ }^{1}$ Division of General Internal Medicine, 5-134C Clinical Sciences Building,

University of Alberta, 1135083 Avenue, Edmonton, AB T6G 2G3, Canada

Full list of author information is available at the end of the article
} 


\section{Background}

Choosing Wisely (https://www.choosingwisely.org), the "Do not do" recommendations from NICE (https://www. nice.org.uk), and various guideline bodies have raised the issue of whether some individuals with type 2 diabetes mellitus may be over-treated in light of observational studies suggesting that the relationship between $\mathrm{HbA1C}$ levels and poor outcomes is U-shaped [1,2]. Certainly, beyond slowing of diabetic retinopathy progression, the benefits of intensive glucose control are uncertain for patients with type 2 diabetes, and are offset by increased risks of hypoglycemic events [and even all-cause mortality in the Action to Control Cardiovascular Risk in Diabetes (ACCORD) trial], especially in the elderly or those with substantial comorbidities [3-5]. Although diabetes guidelines recommend individualization of glycemic control with HbA1c goals of less than 7.0\% in healthy individuals (and $<7.5 \%$ in healthy patients older than 65 years) with less stringent targets in patients with comorbidities or frailty, several recent analyses from the United States demonstrated that many adults with type 2 diabetes had $\mathrm{HbA} 1 \mathrm{C} \leq 7 \%$ with little difference in glycemic control across health states [6-8]. Moreover, only a minority of patients who were potentially over-treated subsequently had their glycemic therapy deintensified [9-11].

In a similar vein, current hypertension guidelines [12, 13] advise individualization of antihypertensive therapy and caution against overtreatment in patients with type 2 diabetes since the ACCORD trial did not demonstrate any reduction in major cardiovascular events with intensive control of systolic blood pressure (SBP) but instead an increase in serious adverse events [14]. A recent systematic review of 49 antihypertensive trials in diabetes also demonstrated that benefit from treatment was only present in those patients with SBP $>140 \mathrm{mmHg}$ [15]. Despite this trial evidence and studies suggesting risk with lower SBP, especially in older patients with comorbidities [16-18], a recent report from the US Veterans Health Administration demonstrated that half of patients with type 2 diabetes had SBP less than $130 \mathrm{mmHg}$ and over one-third had SBP less than $120 \mathrm{mmHg}$ [9].

The purpose of this study is to examine risk factor control (glucose and SBP) in a large cohort of patients with diabetes cared for by UK primary care physicians, to examine whether control varied by health status, and to explore whether patterns of treatment deintensification varied by risk factor level and/or health status.

\section{Methods}

\section{Cohort selection}

We identified all patients aged 20 years or older with diabetes mellitus in the health improvement network (THIN) database based on read clinical encounter codes (akin to diagnostic codes in North American physician billing data) or any diabetic prescriptions (using free word searching in the ontology navigator to select drugs identified by FM as being glucose lowering drugs in the British National Formulary) -full list available from author BCL on request. THIN data collection began in 2003 and by September 2015 more than 670 NHS primary care practices had contributed data from over 14 million patients to THIN, with 4.4 million patients (approximately 7\% of the UK population) actively registered with and followed over time by THIN practices. The THIN dataset is constructed from deidentified data collected from each participating primary care physician's electronic medical record system using standardised coding systems and only reflects those events deemed relevant to the patient's care by their physician since data are recorded for practice and patient management and not directly for research purposes. Specialty clinics are not included in the THIN dataset we accessed but if specialists made recommendations then those accepted by the attending primary care physician were captured. This dataset has been used in over 600 published studies thus far, is representative of the UK population, and the accuracy of diagnostic coding for chronic conditions, such as diabetes, is high, particularly if one combines physician-assigned READ codes with prescription data $[19,20]$.

Our cohort represents a mix of prevalent and incident cases of diabetes seen at 633 THIN-participating clinics between 2003 and 2015. In order to be eligible for this study, patients in the cohort had to have a HbA1C measurement and a SBP measurement at least 6 months after the initial diagnosis of diabetes (to give their physicians time to initiate and titrate management) - for the purposes of this study, these values are defined as the index measurements.

\section{Definition of health status}

For each patient, we calculated the electronic frailty index (eFI) score using all visits and prescriptions in the 24 months prior to and including the date that the HbA1C used to define their glycemic control was drawn (see below). The eFI is based on the cumulative deficit frailty model and can be used to group patients into categories of fit (eFI score $\leq 0.12$ ), mild (eFI 0.13-0.24), moderate (eFI $0.25-0.36)$, and severe $(\mathrm{eFI}>0.36)$ frailty [21]. The eFI was developed in the ResearchOne Database and externally validated in the THIN dataset for patients older than 65 and demonstrates good discrimination for risk of mortality (c statistics of 0.72 and 0.74 in different cohorts), hospitalization (c statistics 0.66 and 0.71 in different cohorts) and nursing home admission (c statistic 0.74 in the ResearchOne cohort). As there were very few patients with eFI scores in the severe range in our cohort 
$(\mathrm{n}=12)$, we grouped moderate and severe frailty for this analysis.

\section{Definition of glycemic control}

We used the HbA1C for each patient recorded at least 6 months after the initial diagnosis of diabetes to define the index date for the glycemia analyses. Mirroring prior publications [2, 14, 15], we grouped treated HbA1C into $<6,6.0-6.4,6.5-6.9,7.0-7.5$, and $>7.5 \%$. We also examined the proportion of patients who met a published definition within the US Veterans Affairs Diabetes Quality Enhancement Research Initiative (https://www. queri.research.va.gov) of "definite glycemic overtreatment": HbA1C $<7 \%$, receiving a sulfonylurea or insulin, and (i) 75 years or older, or (ii) eGFR $<60 \mathrm{~mL} / \mathrm{min}$, or (iii) dementia [8]. In a sensitivity analysis we examined glycemic control in patients who were actively taking glucose lowering medications at the time of the index $\mathrm{HbA1C}$ measurement.

\section{Definition of blood pressure control}

We used the SBP closest to the index HbA1C date to define blood pressure control. Based on prior publications [9], we categorized SBP as < 120, 120-129, 130-139, and $\geq 140 \mathrm{mmHg}$. We also examined the proportion of patients who met a proposed definition of "hypertension overtreatment" for patients with diabetes (also from the VA Diabetes Quality Enhancement Research Initiative, https://www.queri.research.va.gov): SBP $<130 \mathrm{mmHg}$ and (i) receiving at least three antihypertensive drugs, or (ii) starting an additional antihypertensive drug within 90 days of the index SBP measurement, or (iii) increasing dose of antihypertensive drugs within 90 days of the index SBP measurement [22]. In a sensitivity analysis we examined SBP control in patients who were actively taking antihypertensive medications at the time of the index SBP measurement.

\section{Definition of deintensification}

We used the dosgval field in the THIN database (which lists the 25,000 most common drug doses and daily frequencies) to calculate a "glycemic therapy score" and "antihypertensive therapy score" for each patient using prescription records for the 6 months before and after the index measurements. We examined the frequency of treatment deintensification defined as a lower glycemic therapy score (analysis 1) or antihypertensive therapy score (analysis 2) after the index HbA1C or SBP compared to prior to the index measurements. Note that a lower score was obtained if patients stopped (no refill) or were prescribed a lower dose of glucose lowering drugs (analysis 1) or antihypertensive agents (analysis 2) in the 6 months after the index HbA1C (analysis 1) or SBP measurement (analysis 2). As prescription records cannot define daily dose of subcutaneous insulin that the patient actually takes, in a sensitivity analysis we excluded any patients using insulin from the glycemic therapy analysis-as results were not different from the main analysis we did not report them separately. For analysis 1 (glycemic therapy), we compared deintensification rates for patients with index $\mathrm{HbA} 1 \mathrm{C}<6.0,6.0-6.4,6.5-6.9,7.0-$ 7.5 , and $>7.5 \%$. For analysis 2 (antihypertensive therapy), we compared deintensification rates for patients with index $\mathrm{SBP}<120,120-129,130-139$, and $\geq 140 \mathrm{mmHg}$.

\section{Covariates}

The specific variables included are outlined in Table 1we identified comorbidities using previously validated read codes assigned by each patient's primary care physician on their EMR [20]. In patients who did not have some of the laboratory data measured, the missing indicator approach was utilized (patients with missing HbA1C or SBP were excluded).

\section{Statistical analysis}

Patient characteristics were reported as means and standard deviations for continuous variables and proportions for categorical variables. $\mathrm{T}$ tests and one-way ANOVA were used to compare quantitative values between groups. Chi squared tests were used to compare categorical and ordinal values between groups. 95\% confidence intervals were calculated using the Student's t-distribution for quantitative values and the normal approximation to the binomial distribution was used for proportions. As we conducted multiple comparisons the $\mathrm{p}$ value for statistical significance should be $<0.001$ rather than $<0.05$.

\section{Ethics}

As we were using de-identified data, waiver of informed consent was granted by the University of Calgary Health Research Ethics Board (REB15-0203_REN3). This study was based on data from the THIN database obtained by the Cumming School of Medicine at the University of Calgary under license from IQVIA (IMS Quintiles VIAsee https://www.iqvia.com).

\section{Results}

Of 406,649 individuals with diabetes, 297,589 had a HbA1C drawn and 292,703 had a SBP measured at least 6 months after their diabetes diagnosis; the 292,170 with both HbA1C and SBP in the Thin dataset after at least 6 months of diabetes formed the sample for this study (Fig. 1). Mean age was 61.7 years, median time to the index measurements was 354 days (IQR 254-701) after diabetes diagnosis, and the median number of primary 
Table 1 Patient socio-demographics, healthcare utilization, lab results and prescribed drugs up until the time of the index $\mathrm{HbA1C}$ measurement (6 months after diagnosis), stratified according to patient health status

\begin{tabular}{|c|c|c|c|c|c|}
\hline Characteristics & Overall $(n=292,170)$ & $\begin{array}{l}\text { Otherwise fit } \\
(n=270,068)\end{array}$ & $\begin{array}{l}\text { Mild frailty } \\
(n=21,448)\end{array}$ & $\begin{array}{l}\text { Moderate or severe } \\
\text { frailty }(n=654)\end{array}$ & $p$ value \\
\hline Age, mean (SD) & $61.7(15.6)$ & $60.8(15.5)$ & $71.7(12.2)$ & $77.2(11.2)$ & $<0.0001$ \\
\hline Female, \% (n) & $45.2(132,167)$ & $44.3(119,595)$ & $56.7(12,169)$ & $61.6(403)$ & $<0.0001$ \\
\hline $\begin{array}{l}\text { Number of primary care physician visits in the year } \\
\text { prior to index measurement, median }(\mathrm{Q} 1, \mathrm{Q} 3)\end{array}$ & $14(8,21)$ & $13(7,20)$ & $25(16,36)$ & $39(29,54)$ & $<0.0001$ \\
\hline Charlson score, mean (SD) & $1.10(0.92)$ & $1.04(0.86)$ & $1.85(1.28)$ & $2.73(1.6)$ & $<0.0001$ \\
\hline $\begin{array}{l}\text { At least two chronic comorbidities (from the list } \\
\text { below) }\end{array}$ & $8.0(23,464)$ & $5.1(13,768)$ & $42.8(9187)$ & $77.8(509)$ & $<0.0001$ \\
\hline \multicolumn{6}{|l|}{ Specific comorbidities (not mutually exclusive) } \\
\hline Hypertension & $15.6(45,470)$ & $14(37,695)$ & $35(7516)$ & $39.6(259)$ & $<0.0001$ \\
\hline Chronic kidney disease & $1.1(3166)$ & $0.8(2054)$ & $4.8(1038)$ & $11.3(74)$ & $<0.0001$ \\
\hline $\begin{array}{l}\text { Ischemic heart disease (including prior myocardial } \\
\text { infarction or (ABG) }\end{array}$ & $6.0(17,501)$ & $4.4(11,888)$ & $24.9(5334)$ & $42.7(279)$ & $<0.0001$ \\
\hline Heart failure & $1.8(5256)$ & $0.8(2246)$ & $12.8(2748)$ & $40.1(262)$ & $<0.0001$ \\
\hline Cerebrovascular disease & $2.1(6133)$ & $1.7(4701)$ & $6.3(1360)$ & $11.0(72)$ & $<0.0001$ \\
\hline COPD & $3.3(9523)$ & $2.5(6875)$ & $11.6(2489)$ & $24.3(159)$ & $<0.0001$ \\
\hline Cancer & $0.1(347)$ & $0.1(270)$ & $0.3(75)$ & $0.3(2)$ & $<0.0001$ \\
\hline Depression & $4.6(13,484)$ & $4.3(11,585)$ & $8.4(1795)$ & $15.9(104)$ & $<0.0001$ \\
\hline Dementia & $0.6(1818)$ & $0.4(1118)$ & $3.0(647)$ & $8.1(53)$ & $<0.0001$ \\
\hline Urinary incontinence & $1.5(4369)$ & $0.9(2528)$ & $8.0(1707)$ & $20.5(134)$ & $<0.0001$ \\
\hline Arthritis & $5.6(16,476)$ & $4.3(11,687)$ & $21.2(4552)$ & $36.2(237)$ & $<0.0001$ \\
\hline \multicolumn{6}{|l|}{ Diabetes complications } \\
\hline Retinopathy & $5.2(15,131)$ & $4.9(13,114)$ & $9.1(1951)$ & $10.1(66)$ & $<0.0001$ \\
\hline Neuropathy & $0.4(1031)$ & $0.3(823)$ & $0.9(201)$ & $1.1(7)$ & $<0.0001$ \\
\hline Nephropathy & $0.2(566)$ & $0.1(365)$ & $0.9(195)$ & $0.9(6)$ & $<0.0001$ \\
\hline Any of the above & $5.6(16,396)$ & $5.2(14,097)$ & $10.4(2224)$ & $11.5(75)$ & $<0.0001$ \\
\hline \multicolumn{6}{|l|}{ Physical measurements closest to index $\mathrm{HbA} 1 \mathrm{C}$ date } \\
\hline SBP & $138.2(19.4)$ & $138.1(19.3)$ & $139.9(21.3)$ & $137.9(22.6)$ & $<0.0001$ \\
\hline DBP & $79.2(11.0)$ & $79.4(10.9)$ & $77.4(11.8)$ & $74.5(12.5)$ & $<0.0001$ \\
\hline BMI & $30.0(6.9)$ & $30.17(6.9)$ & $28.8(7.1)$ & $26.0(6.8)$ & $<0.0001$ \\
\hline \multicolumn{6}{|l|}{ Lab values } \\
\hline $\begin{array}{l}\text { Estimated glomerular filtration rate category (mL/ } \\
\text { min) }\end{array}$ & $70.7(18.1)$ & $71.3(17.8)$ & $62.7(19.5)$ & $56.5(20.7)$ & $<0.0001$ \\
\hline$<30$ & $1.6(833)$ & $1.3(639)$ & $4.8(181)$ & $9.8(13)$ & $<0.0001$ \\
\hline 30 to $<60$ & $17.6(9089)$ & $16.3(7752)$ & $33.7(1275)$ & $47(62)$ & $<0.0001$ \\
\hline$\geq 60$ & $80.7(41,581)$ & $82.4(39,192)$ & $61.6(2332)$ & $43.2(57)$ & $<0.0001$ \\
\hline Mean (SD) total cholesterol (mmol/L) & $4.77(3.62)$ & $4.78(3.73)$ & $4.66(1.69)$ & $4.41(1.17)$ & 0.007 \\
\hline Mean (SD) triglycerides (mmol/L) & $2.02(1.97)$ & $2.02(2)$ & $1.96(1.41)$ & $1.93(1.41)$ & 0.05 \\
\hline Mean (SD) LDL cholesterol (mmol/L) & $2.6(2.92)$ & $2.61(3.02)$ & $2.43(0.95)$ & $2.15(0.75)$ & 0.001 \\
\hline Mean (SD) HbA1c (\%) & $7.37(1.64)$ & $7.38(1.64)$ & $7.23(1.56)$ & $7.10(1.46)$ & $<0.0001$ \\
\hline \multicolumn{6}{|c|}{ Drugs prescribed within 120 days preceding the index $\mathrm{HbA} 1 \mathrm{C}$ measurement (not mutually exclusive) } \\
\hline Insulin & $17.0(49,623)$ & $16.9(45,740)$ & $17.5(3764)$ & $18.2(119)$ & 0.05 \\
\hline Sulfonylurea & $24.2(70,666)$ & $23.6(63,625)$ & $31.7(6789)$ & $38.5(252)$ & $<0.0001$ \\
\hline Metformin & $48.2(140,964)$ & $48.4(130,620)$ & $46.9(10,058)$ & $43.7(286)$ & $<0.0001$ \\
\hline Thiazolidinedione & $4.2(12,376)$ & $4.2(11,441)$ & $4.2(911)$ & $3.7(24)$ & 0.77 \\
\hline Dipeptidyl peptidase-4 inhibitors & $1.0(2899)$ & $1.0(2684)$ & $1.0(207)$ & $1.2(8)$ & 0.77 \\
\hline Other antidiabetic agents & $1.4(4088)$ & $1.4(3756)$ & $1.5(318)$ & $2.1(14)$ & 0.15 \\
\hline ACE inhibitor/ARB & $46.8(136,812)$ & $45.4(122,711)$ & $63.6(13,637)$ & $70.9(464)$ & $<0.0001$ \\
\hline
\end{tabular}


Table 1 (continued)

\begin{tabular}{lccccc}
\hline Characteristics & Overall $(\mathbf{n = 2 9 2 , 1 7 0 )}$ & $\begin{array}{l}\text { Otherwise fit } \\
(\mathbf{n}=\mathbf{2 7 0 , 0 6 8 )}\end{array}$ & $\begin{array}{l}\text { Mild frailty } \\
(\mathbf{n}=\mathbf{2 1 , 4 4 8})\end{array}$ & $\begin{array}{l}\text { Moderate or severe } \\
\mathbf{f r a i l t y}(\mathbf{n}=\mathbf{6 5 4})\end{array}$ & $\mathbf{p}$ value \\
\hline Statin & $51.9(151,782)$ & $51.3(138,509)$ & $60.1(12,882)$ & $59.8(391)$ & $<0.0001$ \\
Beta blocker & $18.1(52,776)$ & $17.7(47,821)$ & $22.5(4818)$ & $20.9(137)$ & $<0.0001$ \\
Other antihypertensive agents & $71.4(208,666)$ & $70.5(190,427)$ & $82.5(17,696)$ & $83.0(543)$ & $<0.0001$ \\
Antiplatelet agent & $37.9(110,589)$ & $36(97,216)$ & $60.2(12,908)$ & $71.1(465)$ & $<0.0001$ \\
\hline
\end{tabular}

Patient characteristics are reported as means and standard deviations for continuous variables and proportions for categorical variables (with numbers in brackets) Health status defined by eFI score: fit $(\leq 0.12)$, mild frailty (eFI $0.13-0.24)$, moderate frailty (eFI $0.25-0.36)$, and severe frailty (eFI >0.36) [21].
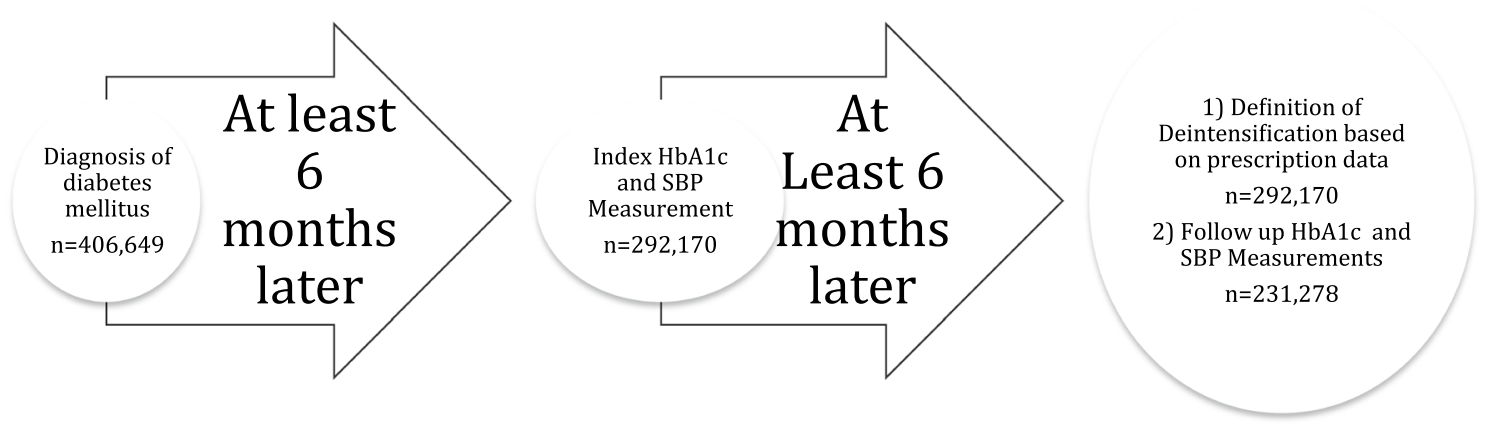

Fig. 1 Study outlined and derivation of study sample

care physician visits in the year prior to the index measurements was 14-ranging from 13 in otherwise fit individuals with diabetes up to 39 in those with moderate or severe frailty (Table 1). Of note, the median time between the index HbA1C and index SBP measurements was 12 days.

Most patients in the study sample were otherwise fit (270,068, 92.4\%), 21,448 (7.3\%) met the definition for mild frailty, $642(0.2 \%)$ moderate frailty, and 12 were severely frail (we lumped moderate and severe frailty together in subsequent analyses). Comorbidities and health resource use were substantially higher as degree of frailty increased (Table 1). Diabetes complications (most commonly retinopathy) were not uncommon, even in the relatively healthy subgroups: $5.2 \%$ of otherwise fit patients and $10.3 \%$ of those classified as having mild frailty had a diabetes complication noted by the time of the index measurements.

\section{Risk factor control}

The mean index HbA1C was $7.4 \%$ in otherwise fit patients, $7.2 \%$ in mildly frail patients, and $7.1 \%$ in moderately-severely frail patients (Table 1). While $37.0 \%$ of patients had index HbA1C $>7.5,15.2 \%$ had $\mathrm{HbA} 1 \mathrm{C}<6 \%$ and $16.4 \%$ had HbA1C $6.0-6.4 \%$ with little change 6 months later: 37.7, 13.1, and 15.9\% respectively (Table 2). Glycemic and SBP control were significantly different across health status strata (Table 2, both $\mathrm{p}<0.001$ ). The proportion of patients with $\mathrm{HbA1C}<6.5 \%$ was lower in otherwise fit patients $(31.3 \%)$ than in mildly frail patients $(34.1 \%)$ or those who were moderately-severely frail $(37.2 \%, \mathrm{p}<0.001)$. Although the sensitivity analysis limited to the 160,322 patients actively taking glucose lowering medications at the time of the index HbA1C measurement found slightly smaller proportions, the patterns were the same $(26.3 \%$ vs. $29.4 \%$ vs. $32.7 \%, \mathrm{p}<0.0001$, Additional file 1: Appendix Table S1). The VA definition of "definite glycemic overtreatment" [8] was met by $3.5 \%$ of patients.

The mean SBP at the time of the index HbA1C measurement was $138.1 \mathrm{mmHg}$ in otherwise fit patients, $139.9 \mathrm{mmHg}$ in mildly frail patients, and $137.9 \mathrm{mmHg}$ in moderately-severely frail patients (Table 1 ). While $46.9 \%$ of patients had index SBP $\geq 140 \mathrm{mmHg}, 12.7 \%$ had SBP $<120 \mathrm{mmHg}$, and $17.1 \%$ had SBP 120 $129 \mathrm{mmHg}$ with very little change 6 months later: $46.6,12.0$, and $17.3 \%$ respectively. The proportion with $\mathrm{SBP}<120 \mathrm{mmHg}$ was lower in otherwise fit patients $(12.7 \%)$ than in mildly frail patients $(13.2 \%)$ or those who were moderately-severely frail $(17.0 \%, \mathrm{p}<0.001)$. Although the sensitivity analysis limited to the 160,322 patients actively taking antihypertensive drugs at the 
Table 2 Glycemic and blood pressure levels in the first year after diagnosis of diabetes

\begin{tabular}{|c|c|c|c|c|c|}
\hline & Overall $(n=292,170)$ & $\begin{array}{l}\text { Otherwise fit } \\
(n=270,068)\end{array}$ & Mild frailty $(n=21,448)$ & $\begin{array}{l}\text { Moderate or severe } \\
\text { frailty }(n=654)\end{array}$ & $p$ value \\
\hline \multicolumn{6}{|c|}{ Index HbA1C (after at least 6 months of management) } \\
\hline$<6 \%$ & $15.2(44,293)$ & $15.0(40,602)$ & $16.6(3559)$ & $20.2(132)$ & $<0.0001$ \\
\hline $6.0-6.4 \%$ & $16.4(47,985)$ & $16.3(44,113)$ & $17.5(3761)$ & $17(111)$ & $<0.0001$ \\
\hline $6.5-6.9 \%$ & $18.1(53,020)$ & $18.1(48,844)$ & $18.9(4055)$ & $18.5(121)$ & 0.01 \\
\hline $7.0-7.5 \%$ & $13.3(38,765)$ & $13.2(35,777)$ & $13.5(2903)$ & $13.0(85)$ & 0.48 \\
\hline$>7.5 \%$ & $37.0(108,107)$ & $37.3(100,732)$ & $33.4(7170)$ & $31.3(205)$ & $<0.0001$ \\
\hline $\begin{array}{l}\mathrm{HbA} 1 \mathrm{C} \text { at least } 6 \text { months } \\
\text { after index } \mathrm{HbA} 1 \mathrm{C}\end{array}$ & Overall $(n=231,278)$ & $\begin{array}{l}\text { Otherwise fit } \\
(n=214,456)\end{array}$ & Mild frailty $(n=16,398)$ & $\begin{array}{l}\text { Moderate or severe } \\
\text { frailty }(n=424)\end{array}$ & $p$ value \\
\hline$<6 \%$ & $13.1(30,260)$ & $12.9(27,740)$ & $14.9(2450)$ & $16.5(70)$ & $<0.0001$ \\
\hline $6.0-6.4 \%$ & $15.9(36,735)$ & $15.8(33,848)$ & $17.1(2812)$ & $17.7(75)$ & $<0.0001$ \\
\hline $6.5-6.9 \%$ & $18.9(43,682)$ & $18.8(40,397)$ & $19.6(3211)$ & $17.5(74)$ & 0.05 \\
\hline $7.0-7.5 \%$ & $14.4(33,338)$ & $14.5(31,015)$ & $13.8(2269)$ & $12.7(54)$ & 0.06 \\
\hline$>7.5 \%$ & $37.7(87,263)$ & $38(81,456)$ & $34.5(5656)$ & $35.6(151)$ & $<0.0001$ \\
\hline \multicolumn{6}{|c|}{ Index systolic blood pressure (after at least 6 months of management) } \\
\hline$<120 \mathrm{mmHg}$ & $12.7(37,216)$ & $12.7(34,266)$ & $13.2(2839)$ & $17.0(111)$ & 0.0003 \\
\hline $120-129 \mathrm{mmHg}$ & $17.1(49,825)$ & $17.2(46,582)$ & $14.6(3139)$ & $15.9(104)$ & $<0.0001$ \\
\hline $130-139 \mathrm{mmHg}$ & $23.3(67,987)$ & $23.5(63,410)$ & $20.8(4455)$ & $18.7(122)$ & $<0.0001$ \\
\hline $140 \mathrm{mmHg}$ or greater & $46.9(137,142)$ & $46.6(125,810)$ & $51.4(11,015)$ & $48.5(317)$ & $<0.0001$ \\
\hline $\begin{array}{l}\text { Systolic blood pressure } \\
6 \text { months after index }\end{array}$ & Overall $(n=247,199)$ & $\begin{array}{l}\text { Otherwise fit } \\
(n=228,210)\end{array}$ & Mild frailty $(n=18,447)$ & $\begin{array}{l}\text { Moderate or severe } \\
\text { frailty }(n=542)\end{array}$ & $p$ value \\
\hline$<120 \mathrm{mmHg}$ & $12.0(29,578)$ & $11.9(27,091)$ & $13.0(2396)$ & $16.8(91)$ & $<0.0001$ \\
\hline $120-129 \mathrm{mmHg}$ & $17.3(42,697)$ & $17.4(39,661)$ & $15.9(2940)$ & $17.7(96)$ & $<0.0001$ \\
\hline $130-139 \mathrm{mmHg}$ & $24.1(59,621)$ & $24.3(55,557)$ & 21.4 (3949) & $21.2(115)$ & $<0.0001$ \\
\hline $140 \mathrm{mmHg}$ or greater & $46.6(115,303)$ & $46.4(105,901)$ & $49.7(9162)$ & $44.3(240)$ & $<0.0001$ \\
\hline
\end{tabular}

time of the index SBP measurement found slightly smaller proportions, the patterns were the same $(10.8 \%$ vs. $13.2 \%$ vs. $15.2 \%$, p < 0.0001 , Additional file 1 : Appendix Table S1). The VA definition of "potential hypertension overtreatment" [22] was met by $11.8 \%$ of our cohort.

\section{Treatment deintensification}

Of 154,691 patients being actively treated with hypoglycemic medications and with prescription data for 6 months before and 6 months after the index HbA1C, $56,129(36.3 \%)$ had their glycemic therapy deintensified (Fig. 2). Followup HbA1C measurements 6 months later went up by a mean of 0.17 (95\% CI 0.16-0.18) in patients who had therapy deintensified but went down by 0.06 (95\% CI 0.05-0.07) in those who did not have deintensification of therapy. Deintensification was more common in patients with moderate-severe frailty $(39.4 \%)$ or mild frailty $(39.9 \%)$ than those who were otherwise fit (36.0\%) - both $\mathrm{p}<0.001$. As expected, deintensification rates differed across HbA1C levels (44.7\% in those with $\mathrm{HbA} 1 \mathrm{C}<6,41.3 \%$ in those with HbA1C 6.0-6.4, 39.2\% with HbA1C 6.5-6.9, 36.4\% with HbA1c 7.0-7.5, and $30.8 \%$ of those with $\mathrm{HbA} 1 \mathrm{C}>7.5 \%, \mathrm{p}<0.001)$. There was no significant interaction between health state and $\mathrm{HbA1C}$ strata in the proportion of patients who had their therapy deintensified ( $\mathrm{p}=0.42$ for the interaction term).

Of 187,852 patients being actively treated with antihypertensive medications and with prescription data for 6 months before and 6 months after the index SBP measurement, $67,625(36.0 \%)$ of patients had their antihypertensive therapy deintensified with a statistically significant but small magnitude difference across BP levels $(39.8 \%$ of those with SBP $<120,37.8 \%$ of those with SBP 120-129, 37.1\% of those with SBP 130-139, and and $34.0 \%$ of those with SBP > $140 \mathrm{mmHg}$-Fig. 3. Deintensification was more common in patients with mild $(38.8 \%)$ or moderate-severe $(43.9 \%)$ frailty than those who were otherwise fit $(35.7 \%)$-both $\mathrm{p}<0.001$. There was no interaction between health state and SBP strata in the proportion of patients who had their therapy deintensified $(\mathrm{p}=0.53)$.

Of note, 17,136 patients had both their glucose lowering and their antihypertensive therapies deintensified in 
$<6$

$6-6.4$

$1.00-$

$0.75-$

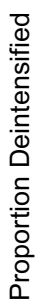

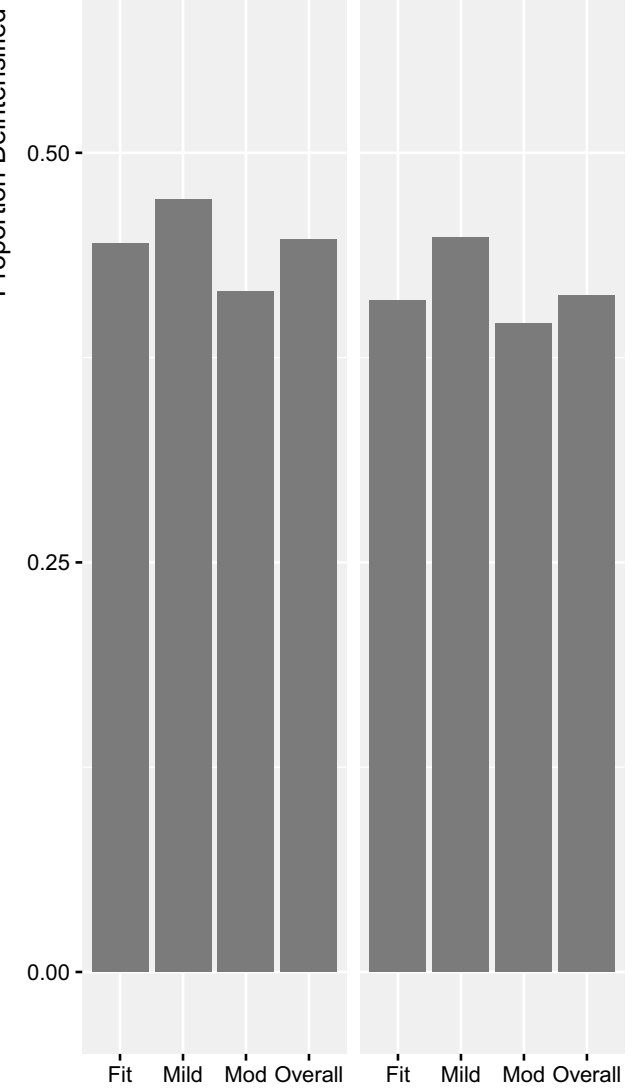

$0.00-$

Fit Mild Mod Overall Fit Mild Mod Overall
$7-7.5$

$>7.5$

$>7.5$

7-7
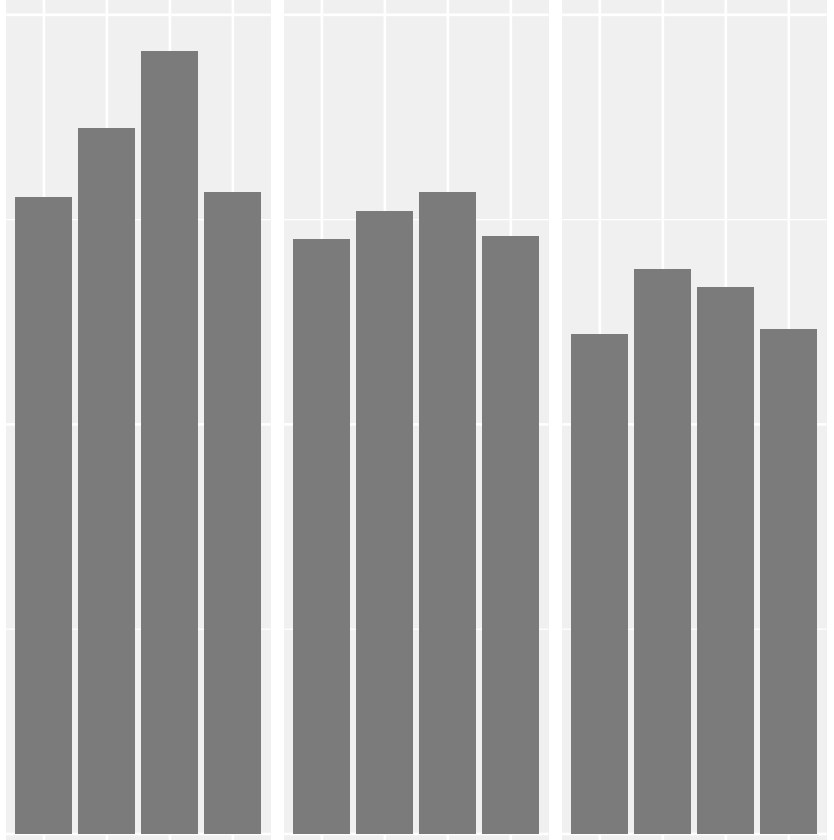

Fit Mild Mod Overall

Fit Mild M'od Overall

Fit Mild M'od Overall Frailty Group

Fig. 2 Proportion of patients with deintensification of glycemic treatment, by health status and within $\mathrm{HbA} 1 \mathrm{C}$ strata

the 6 months after the index measurements (approximately one-sixth of the 106,663 patients who had either therapy deintensified).

\section{Discussion}

We found that glycemic and SBP control was similar for otherwise fit adults with diabetes as for frail patients, 


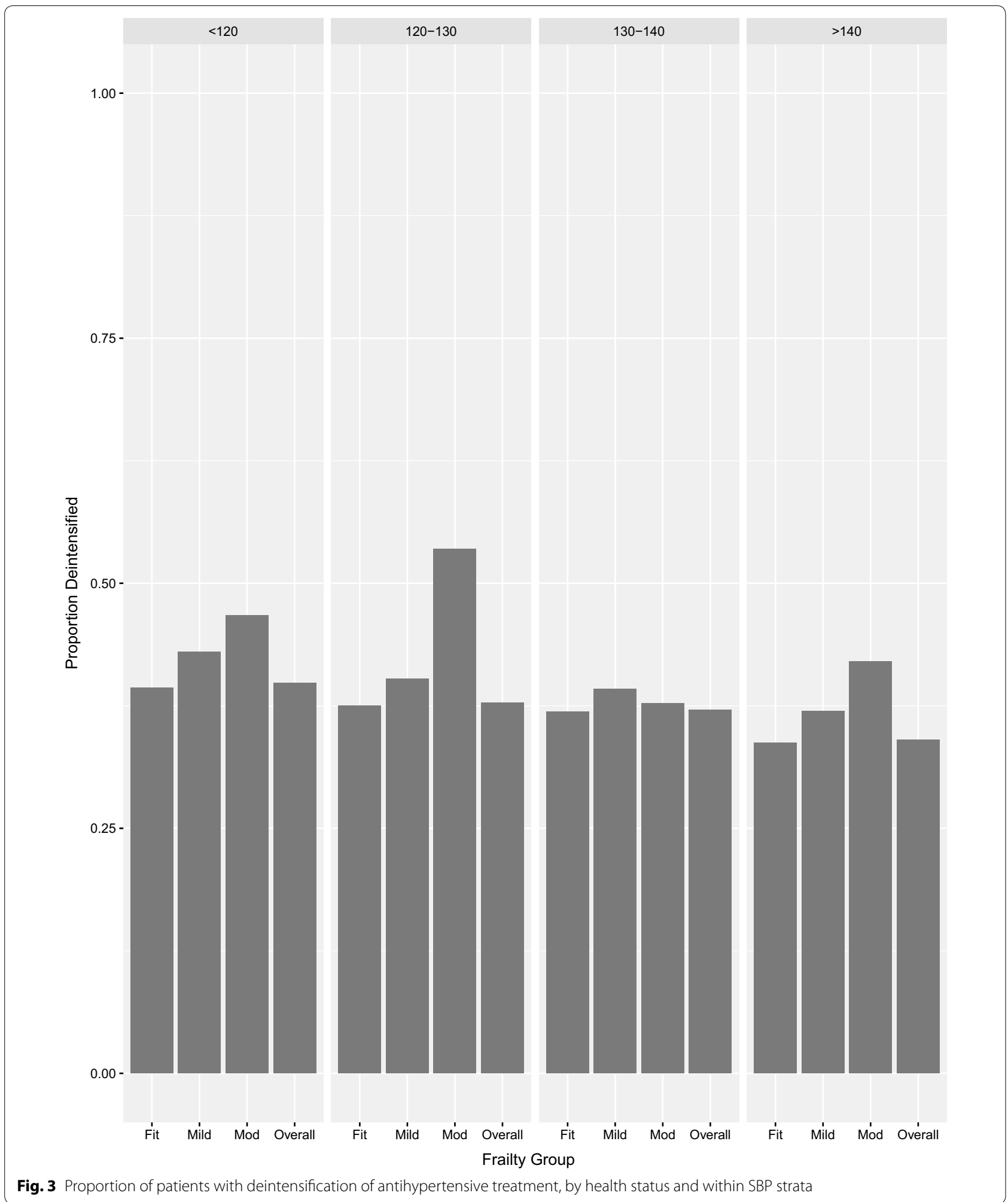

and that while nearly one-third of all diabetic individuals in this cohort of primary care-managed NHS patients had treated $\mathrm{HbA} 1 \mathrm{C}<6.5 \%$ or $\mathrm{SBP}<130 \mathrm{mmHg}$, nearly half had HbA1C $>7.5 \%$ or SBP $>140 \mathrm{mmHg}$. This is in contrast to US Medicare data suggesting that overtreatment is more common than undertreatment in elderly 
Americans [23]. We also found that, although deintensification rates in this UK cohort are nearly double the $14-19 \%$ reported in US-based studies [8-10, 23], therapy was reduced in less than half of patients with low HbA1C or SBP levels, even if they were frail, despite frequent primary care follow-up (median 14 visits per year). On the other hand, it should be noted that even in otherwise fit individuals with diabetes, the proportions with $\mathrm{HbA1C}$ or SBP above recommended targets also differed little when re-measured 6 months later. This echoes an earlier study from the UK Clinical Practice Research Datalink which found that for the vast majority of patients with a new diagnosis of diabetes the HbA1C levels changed little after the first 6 months (followup was out to 24 months) and only $40 \%$ of patients with HbA1C levels above target had any therapy intensification in the subsequent year [24]. A recent analysis of 833 elderly individuals with type 2 diabetes mellitus in Canadian primary care practices reported findings similar to ours: approximately half of healthy older patients had HbA1C and SBP levels above target range, nearly half of frail patients exhibited potential overtreatment, and medication adjustments in either situation were uncommon [25]. Recent reports from China and a registry from 410 sites in 32 other countries also documented that less than half of patients with type 2 diabetes have their HbA1C and SBP controlled within recommended target ranges, although they did not distinguish between potential over- vs. under-treatment [26, 27].

Thus, our data highlight the importance of personalizing targets and multiple potential targets for quality improvement in primary care management of type 2 diabetes. For example, although the emphasis in diabetes professional education programs and guidelines is usually on glucose lowering options $[4,28]$, far more patients in our cohort exhibited uncontrolled hypertension than poor glycemic control-consistent with earlier studies in Canada, the United States, and the Netherlands [22, $28-31]$. This pattern is concerning since blood pressure is the strongest driver of cardiovascular outcomes in diabetic individuals (with an attributable risk nearly three fold greater than glycemic levels in the Framingham study) [32]. The benefits of blood pressure lowering (at least to $<140 \mathrm{mmHg}$ ) $[15,17]$ exceed those of glucose lowering [3-5], and antihypertensive therapy is the most cost-effective of the cardiovascular prevention therapies in type 2 diabetes [33]. Moreover, it should be acknowledged that in all health states uncontrolled hypertension was far more common than over-controlled blood pressure. Thus, our study highlights the need for increased attention to the role of blood pressure control in improving outcomes for individuals with diabetes.
On the other side of the quality equation, although clinical performance measures have until recently almost exclusively focused on under-treatment and failure to meet targets [28, 34], there is increasing recognition of the potential harms that can arise from over-treatment. Intensive lowering of glucose and blood pressure have both been shown to be potentially harmful in individuals with diabetes $[1-3,11,15]$. Although we did not have access to complete data on emergency room visits or hospitalizations for our cohort, other studies have demonstrated that hypoglycemia is one of the most common presenting diagnoses in emergency departments for elderly individuals and results in more frequent and more severe hospitalizations than does hyperglycemia $[35,36]$. Moreover, achieving intensive glycemic or SBP control requires polypharmacy which puts patients at increased risk for drug-drug interactions, poorer medication adherence, and reduced quality of life [16]. While efforts through Choosing Wisely, NICE, and the Veterans Affairs Hypoglycemia Safety Initiative to improve physician awareness of this issue are a welcome addition to the quality improvement landscape in diabetes, educational interventions alone are inadequate to overcome clinical inertia [37]. In fact, preliminary evidence suggests that clinical inertia is an even greater barrier against deintensifying therapy than introducing novel therapies [38, 39].

Although our study has several strengths due to the availability of detailed clinical data in a large population-based sample of patients with new diagnoses of diabetes, there are some limitations to our data. First, to the extent that the primary care clinical records may have under-captured some comorbidities (particularly likely for conditions like dementia, chronic pain, or depression), we may have underestimated the proportion of individuals with multiple comorbidities and thus overstated the proportion who were otherwise fit. Second, we may have underestimated rates of deintensification as we don't know if insulin doses had been decreased or if patients were told to split pills after receiving their prescriptions. Third, although some might see it as a weakness that we used prescription records rather than pharmacy dispensation records, we would argue that this is a strength since it permits us to capture physician intent without the data being confounded by primary non-adherence (patients not filling their prescription). Fourth, while there are various scales for evaluating patient frailty, cumulative deficit models (like the eFI we used) have been shown to better predict functional and mortality outcomes than some of the other scales more commonly quoted in the literature [40]. Fifth, although some antihypertensive 
therapies such as ACE inhibitors or angiotensin receptor blockers are recommended in diabetic individuals with left ventricular dysfunction or significant proteinuria regardless of their SBP, only a very small minority of our cohort had these conditions. Finally, we did not have data on other factors that could influence clinical decision making such as socioeconomic status, specialist involvement in patient care, or patient preferences. Without the fuller picture this data would provide, we elected not to perform multivariate analyses to try to define whether particular comorbidities or patient factors were more likely to be associated with out-of-range HbA1C or SBP levels than other factors to avoid potentially spurious findings.

\section{Conclusion}

In conclusion, although there were statistically significant (but clinically minor) differences in glycemic and hypertensive control across health states, medication changes were uncommon regardless of their health status. Nearly one-third of all diabetic individuals in this cohort had treated $\mathrm{HbA} 1 \mathrm{C}<6.5 \%$ or SBP $<130 \mathrm{mmHg}$ with little difference in proportions when re-measured 6 months later. On the other hand, nearly half of this cohort exhibited poor control of glucose (HbA1C > 7.5\%) or SBP (> $140 \mathrm{mmHg}$ ), with again little change in those proportions 6 months later despite frequent primary care visits. Our study thus highlights the need for personalizing treatment targets in adults with type 2 diabetes and implementing diabetes quality improvement strategies [41] that are flexible enough to focus on both the potential over-treatment of multimorbid patients as well as potential under-treatment of healthier patients and to consider both blood pressure as well as glycemic targets. To that end, it is worth noting that a recent Monte Carlo-based Markov Model decision analysis confirmed that care to achieve individualized treatment targets was cost-saving and associated with a small improvement in quality of life [42].

\section{Additional file}

Additional file 1. Glycemic and blood pressure levels in the first year after diagnosis of diabetes in those patients with active prescriptions at the time of index measurements.

\section{Authors' contributions}

Study conception and design: FM. Data attainment and analysis: BL, CL, ML, TW. Interpretation of data: all authors. First draft of manuscript: FM. Subsequent revisions: All authors. All authors read and approved the final manuscript

\section{Author details}

${ }_{1}^{1}$ Division of General Internal Medicine, 5-134C Clinical Sciences Building, University of Alberta, 1135083 Avenue, Edmonton, AB T6G 2G3, Canada. ${ }^{2}$ Patient
Health Outcomes Research and Clinical Effectiveness Unit, 5-134C Clinical Sciences Building, University of Alberta, 1135083 Avenue, Edmonton, AB T6G 2G3, Canada. ${ }^{3}$ Clinical Research Unit, Cumming School of Medicine, University of Calgary, Calgary, Canada.

\section{Acknowledgements}

FM is supported by the University of Alberta Chair in Cardiovascular Outcomes Research.

\section{Competing interests}

All authors have completed the ICMJE uniform disclosure form at https:// www.icmje.org/coi_disclosure.pdf and declare: no support from any organisation for the submitted work; no financial relationships with any organisations that might have an interest in the submitted work in the previous 3 years; no other relationships or activities that could appear to have influenced the submitted work.

Availability of data and materials

No additional data available.

\section{Consent for publication}

Not applicable.

\section{Ethics approval and consent to participate}

As we were using de-identified data, waiver of informed consent was granted by the University of Calgary Health Research Ethics Board (REB15-0203_REN3). This study was based on data from the THIN database obtained by the Cumming School of Medicine at the University of Calgary under license from IQVIA (IMS Quintiles VIA—see https://www.iqvia.com).

Funding

No project specific funding for this study.

\section{Publisher's Note}

Springer Nature remains neutral with regard to jurisdictional claims in published maps and institutional affiliations.

Received: 12 January 2018 Accepted: 7 February 2018

Published online: 12 February 2018

\section{References}

1. Currie CJ, Peters JR, Tynan A, Evans M, Heine RJ, Bracco OL, et al. Survival as a function of $\mathrm{HbA} 1 \mathrm{c}$ in people with type 2 diabetes: a retrospective cohort study. Lancet. 2010;375:481-9.

2. Nicholas J, Charlton J, Dregan A, Gulliford MC. Recent HbA1C values and mortality risk in type 2 diabetes. Population-based case-control study. PLOS ONE. 2013;8(7):e68008. https://doi.org/10.1371/journal. pone.0068008.

3. Hemmingsen B, Lund SS, Gluud C, Vaag A, Almdal TP, Hemmingsen C, Wetterslev J. Intensive glycaemic control for patients with type 2 diabetes: systematic review with meta-analysis and trial sequential analysis of randomised clinical trials. BMJ. 2011;343:d6898.

4. Rodriguez-Gutierrez R, Montori VM. Glycemic control for patients with type 2 diabetes mellitus: our evolving faith in the face of the evidence. Circ Cardiovasc Qual Outcomes. 2016:9:504-12.

5. Makam AN, Nguyen OK. An evidence-based medicine approach to antihyperglycemic therapy in diabetes mellitus to overcome overtreatment. Circulation. 2017;135:180-95.

6. Lipska KJ, Ross JS, Miao Y, Shah ND, Lee SJ, Steinman MA. Potential overtreatment of diabetes mellitus in older adults with tight glycemic control. JAMA Intern Med. 2015;175:356-62.

7. McAlister FA, Youngson E, Eurich DT. Treated glycosylated hemoglobin levels in individuals with diabetes mellitus vary little by health status: a retrospective cohort study. Medicine. 2016;95:e3894. https://doi. org/10.1097/md.0000000000003894. 
8. Tseng CL, Soroka O, Maney M, Aron DC, Pogach LM. Assessing potential glycemic overtreatment in persons at hypoglycemic risk. JAMA Intern Med. 2014;174:259-68.

9. Sussman JB, Kerr EA, Saini SD, Holleman RG, Klamerus ML, Min LC, Vijan S, Hofer TP. Rates of deintensification of blood pressure and glycemic medication treatment based on levels of control and life expectancy in older patients with diabetes mellitus. JAMA Intern Med. 2015:175:1942-9.

10. McAlister FA, Youngson E, Eurich D. Glycemic treatment deintensification is uncommon in adults with type 2 diabetes mellitus: a retrospective cohort study. Circ CV Qual Outcomes. 2017;10:e003514. https://doi. org/10.1161/circoutcomes.116.003514.

11. McCoy RG, Lipska KJ, Yao X, Ross JS, Montori VM, Shah ND. Intensive treatment and severe hypoglycemia among adults with type 2 diabetes. JAMA Intern Med. 2016;176:969-78.

12. NICE/BHS Hypertension in adults: diagnosis and management. Updated November 2016. https://www.nice.org.uk/guidance/cg127 Accessed 28 July 2017.

13. James PA, Oparil S, Carter BL, Cushman WC, Dennison-Himmelfarb C, Handler J, et al. 2014 evidence-based guideline for the management of high blood pressure in adults: report from the panel members appointed to the Eighth Joint National Committee (JNC 8). JAMA. 2014;311:507-20.

14. Cushman WC, Evans GW, Byington RP, Goff DC Jr, Grimm RH Jr, Cutler JA for the ACCORD Study Group, et al. Effects of intensive blood-pressure control in type 2 diabetes mellitus. N Engl J Med. 2010;362:1575-85.

15. Brunström M, Carlberg B. Effect of antihypertensive treatment at different blood pressure levels in patients with diabetes mellitus: systematic review and meta-analyses. BMJ. 2016;352:i717.

16. Adamsson Eryd S, Gudbjörnsdottir S, Manhem K, Rosengren A, Svensson AM, Miftaraj M, Franzen S, Bjorck S. Blood pressure and complications in individuals with type 2 diabetes and no previous cardiovascular disease: national population based cohort study. BMJ. 2016;354:14070.

17. Benetos A, Labat C, Rossignol P, Fay R, Rolland Y, Valbusa F, et al. Treatment with multiple blood pressure medications, achieved blood pressure, and mortality in older nursing home residents: the PARTAGE study. JAMA Intern Med. 2015;175:989-95.

18. Tinetti ME, Han L, Lee DSH, McAvay GJ, Peduzzi P, Gross CP, et al. Antihypertensive medications and serious fall injuries in a nationally representative sample of older adults. JAMA Intern Med. 2014;174:588-95.

19. Blak BT, Thompson M, Dattani H, Bourke A. Generalisability of the health improvement network (THIN) database: demographics, chronic disease prevalence and mortality rates. Informat Prim Care. 2011;19:251-5.

20. Herrett E, Thomas SL, Schoonen WM, Smeeth L, Hall AJ. Validation and validity of diagnoses in the general practice research database: a systematic review. Br J Clin Pharmacol. 2010;69:4-14.

21. Clegg A, Bates C, Young J, Ryan R, Nichols L, Ann Teale E, et al. Development and validation of an electronic frailty index using routine primary care electronic health record data. Age Ageing. 2016;45:353-60.

22. Kerr EA, Lucatorto MA, Holleman R, Hogan MM, Klamerus ML, Hofer TP, et al. Monitoring performance for blood pressure management among patients with diabetes mellitus: too much of a good thing? Arch Intern Med. 2012;172:938-45.

23. Maciejewski ML, Mi Z, Sussman J, Greiner M, Curtis LH, Ng J, et al. Overtreatment and deintensification of diabetic therapy among medicare beneficiaries. J Gen Intern Med. 2018;33:34-41.

24. Paul SK, Klein K, Thorsted BL, Wolden ML, Khunti K. Delay in treatment intensification increases the risk of cardiovascular events in patients with type 2 diabetes. Cardiovasc Diabetol. 2015:14:100.

25. Meneilly GS, Berard LD, Cheng AYY, Lin PJ, MacCallum L, Tsuyuki RT, et al. Insights into the current management of older adults with type 2 diabetes in the Ontario primary care setting. Can J Diabetes. 2018;42:23-30.

26. Tao X, Li J, Zhu X, Zhao B, Sun J, Ji L, et al. Association between socioeconomic status and metabolic control and diabetes complications: a cross-sectional nationwide study in Chinese adults with type 2 diabetes mellitus. Cardiovasc Diabetol. 2016;15:61.

27. Masmiquel L, Leiter LA, Vidal J, Bain S, Petrie J, Franek E, et al. LEADER 5: prevalence and cardiometabolic impact of obesity in cardiovascular high-risk patients with type 2 diabetes mellitus: baseline global data from the LEADER trial. Cardiovasc Diabetol. 2016;15:29.

28. Rodriguez-Gutierrez R, Singh Ospina N, McCoy RG, Lipska KJ, Shad ND, Montori VM. Inclusion of hypoglycemia in clinical practice guidelines and performance measures in the care of patients with diabetes. JAMA Intern Med. 2016;176:1714-6.

29. De Vries ST, Voorham J, Haaijer-Ruskamp FM, Denig P. Potential overtreatment and undertreatment of diabetes in different age groups in primary care after the introduction of performance measures. Diabetes Care. 2014;37:1312-20.

30. Saydah SH, Fradkin J, Cowie CC. Poor control of risk factors for vascular disease among adults with previously diagnosed diabetes. JAMA. 2004;291:335-42.

31. Brown LC, Johnson JA, Majumdar SR, Tsuyuki RT, McAlister FA. Evidence of suboptimal management of cardiovascular risk in patients with type 2 diabetes mellitus and symptomatic atherosclerosis. CMAJ. 2004;171:1189-92.

32. Chen G, McAlister FA, Walker RL, Hemmelgarn BR, Campbell NRC. Cardiovascular outcomes among individuals with diabetes: the importance of blood pressure in the Framingham study. Hypertension. 2011:57:891-7.

33. The CDC Diabetes Cost-effectiveness Group. Cost-effectiveness of intensive glycemic control, intensified hypertension control, and serum cholesterol level reduction for type 2 diabetes. JAMA. 2002;287:2542-51.

34. Newton EH, Zazzera EA, van Moorsel G, Sirovich BE. Undermeasuring overuse - an examination of national clinical performance measures. JAMA Intern Med. 2015:175:1709-11.

35. Budnitz DS, Lovegrove MC, Shehab N, Richards CL. Emergency hospitalizations for adverse drug events in older Americans. N Engl J Med. 2011;365:2002-12.

36. Lipska KJ, Ross JS, Wang Y, Inzucchi SE, Minges K, Karter AJ, et al. National trends in US hospital admissions for hyperglycemia and hypoglycemia among Medicare beneficiaries, 1999 to 2011. JAMA Intern Med. 2014;174:1116-24

37. Majumdar SR, MCAlister FA, Furberg CD. From publication to practice in chronic cardiovascular disease - the long and winding road. J Am Coll Cardiol. 2004;43:1738-42.

38. Niven DJ, Rubenfeld GD, Kramer AA, Stelfox HT. Effect of published scientific evidence on glycemic control in adult intensive care units. JAMA Intern Med. 2015;175:801-9.

39. Kerr EA, Hofer TP. Deintensification of routine medical services. The next frontier for improving care quality. JAMA Intern Med. 2016;176:978-80.

40. Clegg A, Young J, Iliffe S, Rikkert MO, Rockwood K. Frailty in elderly people. Lancet. 2013;381:752-62.

41. Tricco AC, Ivers NM, Grimshaw JM, Moher D, Turner L, Galipeau J, et al. Effectiveness of quality improvement strategies on the management of diabetes: a systematic review and meta-analysis. Lancet. 2012;379:2252-61.

42. Laiteerapong N, Cooper JM, Skandari MR, Clarke PM, Winn AN, Naylor $\mathrm{RN}$, et al. Individualized glycemic control for U.S. adults with type 2 diabetes: a cost-effectiveness analysis. Ann Intern Med. 2017. https://doi. org/10.7326/m17-0537 (Epub ahead of print 12 December 2017)

\section{Submit your next manuscript to BioMed Central and we will help you at every step:}

- We accept pre-submission inquiries

- Our selector tool helps you to find the most relevant journal

- We provide round the clock customer support

- Convenient online submission

- Thorough peer review

- Inclusion in PubMed and all major indexing services

- Maximum visibility for your research

Submit your manuscript at www.biomedcentral.com/submit 